\title{
ATTILIO CORRÊA LIMA E O PLANEJAMENTO DE GOIÂNIA - UM MARCO MODERNO NA CONQUISTA DO SERTÃO BRASILEIRO
}

\section{Patrick Di Almeida Vieira}

Arquiteto, Doutorando em Arquitetura e Urbanismo pelo Programa de Pós- Graduação e Pesquisa da Faculdade de Arquitetura e Urbanismo da Universidade de Brasília.

\section{Resumo}

O presente texto busca analisar a atuação do arquiteto Attilio Corrêa Lima no planejamento da cidade de Goiânia inclusive a ruptura dos trabalhos na condução do mesmo e as modificações sofridas pelo seu projeto inicial, levantando para tal fim um breve histórico de sua formação e atuação profissional, apontando suas principais experiências e explicitando seus referenciais teóricos. O plano para Goiânia pode ser considerado um marco na conquista do sertão brasileiro, bem como um marco da arquitetura moderna brasileira e é aqui analisado do ponto de vista da mudança de algumas concepções urbanísticas na transição da condução dos trabalhos de Attilio Corrêa Lima para Armando Augusto de Godoy.

Palavras-chave: Urbanismo, Attilio Corrêa Lima, Goiânia.

\begin{abstract}
The present text aims to analyses the role of the architect Attilio Corrêa Lima on Goiânia's planning including as well the rupture of the work in its conduction and the modifications suffered by the original plan, performing a short historic of his formation, professional background, pointing out his main professional achievements and his theoretical references. Goiânia's plan can be considered a mark of brazilian hinterland conquest and a mark of modern brazilian architecture as well. It is analyzed from the perspective of the changing of some urban features at the transition from Attilio Corrêa Lima's work to Armando de Godoy.
\end{abstract}

Keywords: Urbanism, Attilio Corrêa Lima, Goiânia. 


\section{Attilio Corrêa Lima: atuação profissional e pensamento urbanístico}

Attilio Corrêa Lima (figura 1) nasceu em Roma, em 08 de Abril de 1901. Seu pai foi professor da Escola Nacional de Belas Artes do Rio de Janeiro, mesma escola que Corrêa Lima se matriculou como "aluno livre" em sua adolescência. Em 1920, ingressou no curso de arquitetura, diplomando-se engenheiro-arquiteto em 1925. Foi um nome importante na história do desenvolvimento do modernismo brasileiro.

Corrêa Lima não produz extensas reflexões teóricas sobre a arquitetura moderna ou sobre a relativamente nova ciência do urbanismo, mas com sua extensa atuação profissional em seus breves anos de vida dá testemunho de sua adesão aos princípios da nova maneira de se fazer e pensar a arquitetura. Segawa nos diz que Lima já na segunda metade da década de 30 faz parte de uma geração de arquitetos que trabalham para a assimilação das tendências modernizantes não acadêmicas, em diversas cidades brasileiras (Segawa, 1999: 85).

Attilio atua como arquiteto e urbanista em um momento em

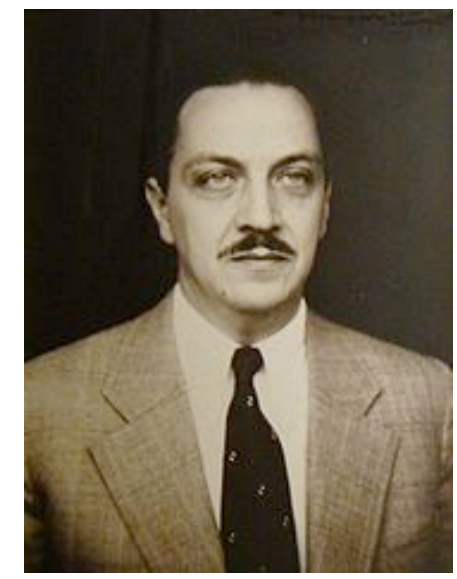
que a produção modernista se encontra em plena ebulição, Figura 1 - Attilio Corrêa Lima. Fonte: MIS-Goiás com experimentações de todas as ordens pelo mundo afora. O modernismo na arquitetura foi a resposta, no ambiente construído, ao programa político e econômico da modernidade, que prometia à humanidade a liberdade dos indivíduos das antigas amarras feudais. 
A modernidade prometia um novo homem capaz de pensar por si mesmo sem necessitar da tutela dos estamentos superiores daquela sociedade. Os arquitetos precisaram de alguma maneira responder a novo estado de coisas repensando os edifícios e cidades; muitas vezes refazendo as cidades.

Em um primeiro momento, os arquitetos, urbanistas, engenheiros, médicos, reformadores sociais imaginaram novas cidades, onde o sonho da igualdade fosse possível e orientado por um planejamento quase onisciente ancorado no uso irrestrito da razão. Tais cidadelas utópicas não vingam e, em meados do século XVIII, os técnicos irão repensar as cidades usando como medida a Paris de Haussmam e a Barcelona de Cerdà.

Corrêa Lima participa ainda em 1925 de um concurso para a Ponta do Calabouço, promovido pela prefeitura do Rio de Janeiro, acabando em segundo lugar, mas este o leva a participar de uma equipe de obras da própria prefeitura, permanecendo ali até 1926. Neste ano, participa de outro concurso, desta vez na Escola Nacional de Belas Artes. O arquiteto conquista a viagem de estudos equivalente a um doutorado - oferecida e passa os próximos quatro anos estudando urbanismo no Instituto de Urbanismo da Universidade de Paris (IUUP).

Em seu retorno de Paris, Lima é nomeado pelo então diretor da Escola Nacional de Belas Artes, Lúcio Costa, para assumir a cadeira de urbanismo na escola. Com a destituição de Lucio Costa e o início da administração do conservador Archimedes Memória, as mudanças na instituição são abortadas antes mesmo de terem início.

Quando do primeiro concurso para professor da Escola Nacional de Belas Artes, Corrêa Lima se apresentou como postulante à vaga, mas teve o dissabor de não ser aprovado devido a pressões políticas sofridas pelo diminuto grupo de professores progressistas que haviam sobrevivido à saída de Lúcio Costa. Sentindo-se injustiçado, Lima entra com um recurso contra a decisão final da comissão conseguindo sua admissão. Em 1937, demite-se por sentir-se desprezado no cargo.

Respaldado pelo prestígio do diploma de urbanista conquistado em Paris, Corrêa Lima é convidado para elaborar o plano da nova capital do Estado de Goiás. Este é um dos seus primeiros trabalhos, sendo contratado em julho de 1933. O prazo era exíguo - meros seis meses - e a mudança da capital era absolutamente necessária no entender do grupo que intentava a derrubada da elite rural dominante. 
A mudança da capital se encaixava perfeitamente no espírito da "revolução" de 1930. Attilio elabora o plano piloto de Goiânia entre 1933 e 1934, entregando-o ao interventor Pedro Ludovico Teixeira em janeiro de 1935 e tendo com isso seu contrato com o governo local extinto.

Com a conclusão de seu trabalho para o governo de Goiás, Lima se envolveu com um plano de remodelação de Recife se atendo aos métodos aprendidos no Instituto de Paris. Nesse trabalho, integrou uma equipe que também eracomposta por nomes caros à arquitetura moderna brasileira como o jovem Roberto Burle Marx e Luis Nunes ${ }^{1}$.

Attilio Corrêa Lima desenvolve outras atividades como arquiteto no decorrer dos anos que se seguem, como, por exemplo, o projeto do conjunto residencial Várzea do Carmo, construído em São Paulo e destinado à classe operária. No caso do conjunto residencial, os princípios utilizados foram aqueles ligados à teoria moderna com o desenvolvimento de vários tipos de plantas. O conjunto foi apenas parcialmente construído, mas serviu, de forma pioneira, de exemplo para um grande número de conjuntos de moradia a partir de 1940.

O projeto da Estação de Hidroaviões do Aeroporto Santos Dumont é de 1938 e fica patente a completa adesão por parte de Lima ao ideário moderno. Segundo Segawa: "havia participado da equipe que tirou o segundo lugar no concurso do terminal terrestre (...) dada a urgência de um terminal aeroviário para o Rio de Janeiro, o projeto de Corrêa Lima foi rapidamente executado, estando em funcionamento em 1938." (Segawa, 1999, 88) Ainda segundo Segawa, o terminal projetado pelo arquiteto transformou-se em uma obra bastante admirada por seu conceito formal, e que se tornou uma referência de um tipo de arquitetura moderna que se fazia na década de 1930.

Outro exemplo da intensa produção de Corrêa Lima foi a Cidade Operária de Volta Redonda, elaborada em 1941. Nesse projeto, percebe-se que Lima faz referência à Cidade Industrial de Tony Garnier na estruturação da proposta do assentamento a partir da adaptação do traçado entre as montanhas ao sul e a estrada de ferro que servia de divisão entre a cidade e a indústria siderúrgica. Ao

\footnotetext{
${ }^{1}$ Luis Carlos Nunes de Souza dirigiu-se em 1934 para Recife na tentativa de organizar uma inédita repartição de arquitetura - autônoma da engenharia - dentro da Secretaria de Obras Públicas, numa iniciativa administrativa modernizante do governador Carlos de Lima Cavalcanti (...) ele pretendia que os projetos fossem elaborados dentro de um "critério único" na perspectiva de introduzir novos métodos e materiais de construção, desenvolvidos a partir de pesquisas e ensaios tecnológicos.(SEGAWA, 1999:83-84.)
} 
contrário de Goiânia, até por motivos óbvios, o sistema viário da proposta do arquiteto, em Volta Redonda, se caracterizava pela ausência de monumentalidade, tendo ele preferido um desenho mais contido com um traçado econômico. Em 1943, Attilio Corrêa Lima recebeu outro convite, desta vez para a elaboração do plano urbanístico da Fábrica Nacional de Motores. O projeto acabou não sendo executado, embora o arquiteto tenha entregado um parecer bastante detalhado acerca do plano com o estudo de vários índices urbanísticos para o melhoramento da qualidade de vida dos trabalhadores. O plano demonstrava um grande apreço pelo rigor técnico e pela racionalidade da proposta Este projeto acabou sendo seu último já que Lima morreu em um acidente de avião quando voltava de São Paulo para o Rio de Janeiro, em 1943, aos 42 anos.

\section{A Atuação de Attilio Corrêa Lima em Goiânia}

Na década de 1930, dentro do contexto da "revolução" promovida por Getúlio Vargas e seu grupo, a implantação de uma capital moderna em pleno sertão do Brasil central poderia soar como uma loucura, mas para o governo federal constituído o significado era estratégico, pois apontava para a direção da fronteira a ser explorada, uma enorme porção do território pronta para ser incorporado ao sistema capitalista periférico que o grupo varguista tentava articular. Para o grupo mudancista de Goiás, a transferência da capital para uma cidade totalmente nova significava, em grande medida, o rompimento com o isolamento e a estagnação que o Estado vivia até então. O isolamento vivido por Goiás representava descrédito para o Estado, agravado pela crise financeira oriunda da quebra da bolsa de Nova Iorque em 1929.

O plano de Goiânia foi confiado pelo interventor federal do Estado, Pedro Ludovico Teixeira, à Attilio Corrêa Lima por meio de um convite que partiu do próprio governador em 1932. A partir do convite feito, estava nas mãos de Corrêa Lima o desafio de satisfazer a contento as aspirações de uma elite urbana goiana em formação e fazer pelo Estado o mesmo que a nova cidade de Belo Horizonte fez por Minas Gerais, colocar o Estado no diapasão da expansão dos mercados da periferia do capitalismo ligando suas novas elites urbanas aos fluxos do capital. Dessa forma, na visão desta elite, a cidade planejada por Lima deveria promover a ação civilizatória ao prever o espaço apropriado para as funções econômicas e ao ordenar de certa forma o desenvolvimento social da nova região de fronteira.

A primeira ação de Corrêa Lima foi modificar ligeiramente a localização da 
futura cidade em relação ao que havia sido estabelecido pela comissão designada para elaborar o programa referente à nova capital. É interessante perceber na explicação de Lima a utilização plena da racionalidade característica da modernidade fazendo uso inclusive de linguagem que aproximava a nova ciência do urbanismo com o conhecimento científico stricto sensu das ciências biológicas.

Foi inicialmente indicado o local denominado de Paineiras, para o assentamento do núcleo inicial. Discordamos dessa opinião por ser o local muito deslocado da estrada de rodagem. Sendo a estrada a artéria vivificadora do organismo urbano, tudo indicava queo núcleo central em formação deva ser atravessado por aquela.

A configuração do terreno também para isso concorreu; sua formação sedimentar dá-Ihe um perfil côncavo, isto é, com declividade decrescente. Ora, um núcleo urbano, se construído na "Paineira", assentaria sobre um terreno de três a quatro por cento de declividade, ao passo que, mais abaixo, no local por nós escolhido, essa declividade é em média de dois por cento; portanto muito mais propício paraconter a parte centra da cidade (LIMA, 1937: 140-141).

Na concepção urbanística de Attilio Corrêa Lima para Goiânia, o elemento urbano mais importante era a praça central, foco privilegiado das perspectivas engendradas pelas principais vias traçadas - avenidas Goiás, Tocantins e Araguaia conforme se pode perceber pela figura 2.

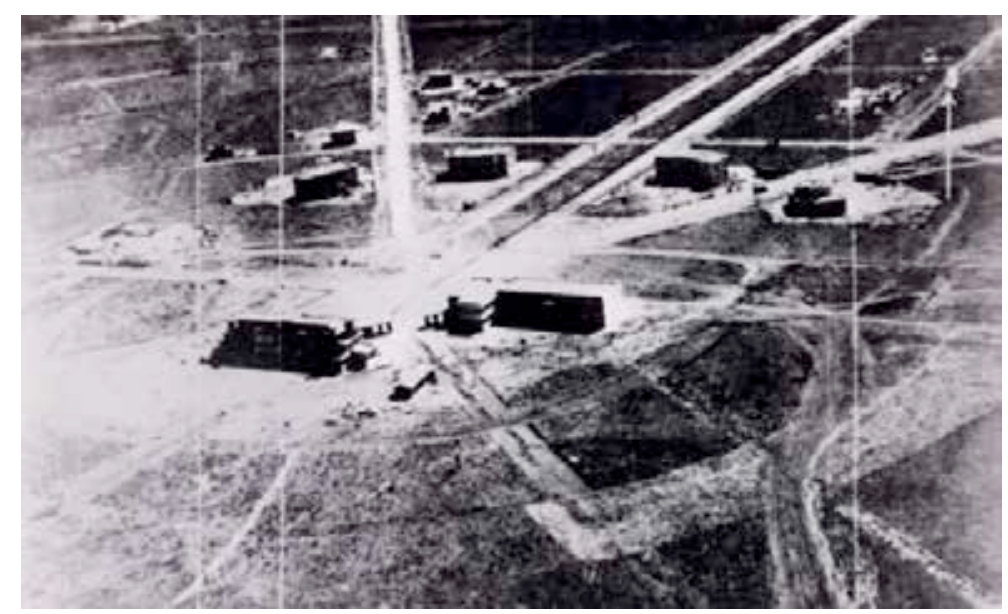

Figura 2 - A Praça Cívica, elemento central na concepção de Attilio Corrêa Lima, ainda na década de 1930. Percebem-se já os três eixos principais convergindo para o palácio do governo. Autor: Antonio Pereira da Silva.

Fonte: MIS-Goiás

Lima considerava que uma capital necessitava da imponência monumental e, para tanto, lançou mão, na nova cidade, do expediente formal do pâte d'oie nascendo em 
frente ao palácio do governo estadual. Lima afiançava que: "guardando as devidas proporções, o efeito monumental procurado é o do princípio clássico adotado em Versalhes, Karlsruhe e Washington" (LIMA, 1937). A influência francesa é claramente notada na solução adotada pelo arquiteto em relação à geometria das avenidas, da praça e na solução estética dos bulevares.

Do estudo de Lima para o planejamento de Goiânia, é possível inferir, em uma forma embrionária e ainda muito incipiente, um planejamento regional pelo fato do arquiteto ter levado em conta a pequena cidade de Campinas, nas proximidades do sítio escolhido, em consideração ao demonstrar o interesse em preservá-la e não como um obstáculo ao desenvolvimento da nova cidade, mas como elemento a ser levado em conta no futuro desenvolvimento da nova capital. Tal preocupação pode ser aduzida da transformação da velha estrada - que dava acesso à Campinas e a outros pequenos arraiais no entorno - na Avenida Anhanguera, que já no final da década de 1940 assumirá posto de grande importância na hierarquização das vias e do tráfego da futura capital. A Avenida Anhanguera recebeu por parte do arquiteto a proposta de um parque linear no cruzamento do eixo norte-sul, onde se concentrariam o comércio e o tráfego mais intenso.

Corrêa Lima demonstra particular atenção a questões como as de zoning, topografia, áreas verdes, hierarquia das vias e tráfego. Esta preocupação comunica inapelavelmente a maturação, no pensamento urbanístico nacional, das questões centrais do urbanismo desde o seu nascimento na condição de disciplina científica. Corrêa Lima deixa evidente que para atender plenamente à vida moderna o plano de uma cidade deveria ter em conta a independência econômica da cidade, além de se preocupar com os outros elementos já mencionados anteriormente.

O zoning é encarado no urbanismo moderno deste período como a grande ferramenta para o satisfatório sucesso do planejamento urbano. Os escritos de Prestes Maia (1950) sobre o plano elaborado por ele para a cidade de Santos deixam isso muito claro, uma vez que Maia separa um capítulo inteiro para esclarecer sobre a importância do zoneamento no planejamento das cidades. Corrêa Limaentende que o zoneamento deveria ser aplicado de uma forma que não limitasse em demasia a liberdade do proprietário e, por isso, mesmo abraçando o ideario moderno, o zoning em Goiânia não foi tão rigoroso. A cidade foi dividida em cinco grandes zonas com os usos separados: A praça central concentrando toda a estrutura administrativa do Estado e município; um setor comercial na confluência da Avenida Pedro Ludovico (futura Avenida Goiás, um dos três eixos principais que nascem da praça central) com 
a Avenida Anhanguera; a região norte da cidade, no outro extremo do eixo principal, próximo à estação de ferro, esta em posição de destaque fazendo um contraponto com o próprio palácio em um dos pólos visuais da principal perspectiva elaborada pelo arquiteto - notamos aqui a adoção de um princípio caro às cidades jardins ${ }^{2}$ seria dedicada às indústrias, os setores sul e oeste seriam eminentemente voltados para as residências suburbanas e as demais áreas identificadas como rurais. Em suas palavras:

O zoneamento da cidade é feito procurando satisfazer as tendências modernas de localizar as diversas atividades da cidade em zonas demarcadas, a fim de não só melhor obter a organização dos serviços públicos, como também para facilitar certos problemas técnicos, econômicos e sanitários, não falando aqui na questão estética.

Se em todas as aglomerações existentes, o zoneamento constitui um problema de difícil solução, para uma cidade que se forma é relativamente fácil, apesar de exigir que seja observada a mais rigorosa vigilância em torno do regulamento das zonas.

Evitamos levar o zoneamento aos rigores extremos, como querem alguns profissionais, porque os excessos têm sempre efeito negativo, como, por exemplo, as inúmeras subdivisões da zona residencial (LIMA, 1937: 142).

Outra preocupação de Corrêa Lima foi com a arborização da cidade. A solução encontrada foi a da constituição de parques e avenidas parques entremeados por pequenos lagos. No entanto, Graeff (1985: 13) afiança que ao propor um tratamento paisagístico de avenida parque, com renque central de árvores frondosas, fechando a perspectiva, Corrêa Lima acaba por eliminar os efeitos intencionados por essa mesma perspectiva e que daria às três avenidas convergentes a expressão anunciada e, assim, na ausência de alamedas, o pitoresco vigorou sobre o monumental. 0 abastecimento de água foi um ponto bastante estudado por Lima com a sugestão do aproveitamento e preservação do rio que abasteceria a cidade bem como de seus afluentes. Nesse sentido, Corrêa Lima apresentou ao governador uma proposta de delimitação rigorosa do perímetro urbano da cidade para que fosse prevenida pelo Estado a deterioração a bacia da região através da aquisição dos terrenos. Aqui também percebemos uma intenção regional do planejamento.

Além dos projetos arquitetônicos e urbanísticos, Corrêa Lima teve a preocupação de propor para o Estado um projeto de organização administrativa e um regulamento para as construções da cidade, o primeiro com a finalidade de separar a

\footnotetext{
${ }^{2}$ Unwin observava que a estação ferroviária deveria ficar em destaque e, diante dela, deveria se situar uma grande praça aberta para acolher as pessoas que chegavam e saíam.
} 
cidade das influências políticas e especulativas e o segundo procurando definir o regulamento urbanístico. Percebe-se uma preocupação que extrapola a arquitetura, considerando a cidade em várias dimensões inclusive aquela política. Lima entregou em 1935 ao governo do Estado um conjunto de projetos que situava o plano de Goiânia na vanguarda da discussão urbana do entre guerras com a predominância de espaços para as vias públicas, jardins e parques. Seu plano estruturava uma grande fluência para o tráfego e continham uma grande preocupação com o bem estar dos munícipes a partir do desenho das ruas de cada bairro. Com a entrega dos planos em janeiro de 1935, Attilio Corrêa Lima foi desligado das obras já em andamento.

\section{A transição da condução dos trabalhos}

São incertos os motivos que levaram ao rompimento entre o arquiteto Attilio Corrêa Lima e o governo do Estado de Goiás. Em uma entrevista, Corrêa Lima oferece uma explicação para o seu desligamento da equipe de construção da nova capital:

Inúmeras foram as dificuldades que tivemos de vencer, os recursos financeiros eram ínfimos e os métodos de construção ainda primitivos. (...) Foi tremenda, a luta (...). Em pleno sertão devíamos construir uma cidade.

Três fatores deveríamos enfrentar: a dificuldade de obter material - ainda inexplorado na ocasião; o problema da mão de obra - deficiente, não adaptada aos métodos modernos de construir - e, finalmente, os transportes para o material vindo de fora.

E como se não bastassem as dificuldades acima descritas, tivemos a luta política desencadeada pela oposição durante o período da propaganda eleitoral e a luta subterrânea de resistência passiva movida pelos interesses prejudicados na mudança do centro vital do Estado (LIMA, 1942: 50).

A necessidade de transferência do arquiteto do Rio de Janeiro para o planalto central também, segundo o próprio Attilio, forneceu motivação extra para o abandono das obras. Além disso, Corrêa Lima continuava vinculado à Escola Nacional de Belas Artes ocupando-se da cadeira de Urbanismo, cargo que ocuparia até 1937. Em 1934, o arquiteto foi nomeado, pelo Ministério da Educação, membro do Conselho Nacional de Belas Artes. Em suma, não faltavam elementos para dificultar a permanência de Corrêa Lima à frente das obras de Goiânia.

Do lado do governo, a justificativa se deu pelo fato de Corrêa Lima não conseguir acompanhar as exigências nos prazos estipulados no contrato. Os irmãos Coimbra Bueno afirmaram que o arquiteto também alegava incapacidade financeira 
de arcar com os constantes deslocamentos do Rio de Janeiro para Goiânia, uma vez que os custos de tal empreitada não estavam previstos em contato.

Com a suspensão da prestação de serviços ao governo do Estado por parte de Attilio Corrêa Lima, o engenheiro Armando de Godoy assumiu a incumbência de ser o consultor técnico dos construtores de Goiânia, os irmãos Coimbra Bueno.

A relação de Godoy com Goiânia não era algo novo. Tendo participado de discussões anteriores ao projeto de Corrêa Lima, na condição de consultor do grupo de trabalho responsável pela mudança da capital do Estado de Goiás ${ }^{3}$.

\section{As mudanças do projeto original}

Em um dos relatórios dos irmãos Coimbra Bueno, em 1936, pode-se notar certo tom de desmerecimento em relação ao plano original de Attilio Corrêa Lima. Conforme já dito anteriormente, Corrêa Lima, no seu relatório, indicou formas de proteger a nova cidade das influências políticas de forma a garantir a integridade formal e conceitual de Goiânia. Isso certamente contrariava muitos e poderosos interesses, a começar pelos interesses dos irmãos Coimbra Bueno, donos de grandes glebas e da empresa encarregada da construção da cidade. Eles manifestaram junto ao governador o interesse de submeter o projeto do Corrêa Lima a uma análise externa, possivelmente já com a intenção de inviabilizar alguma parte do projeto integral.

É bastante provável que o impulso inicial para a revisão do projeto do arquiteto tenha partido da pressão para o loteamento dos arrabaldes da nova capital. A propaganda, no país todo, incentivando o investimento em Goiânia provocou grande afluxo de pessoas fazendo disparar o preço da terra. No entanto, nesse momento, o controle sobre a expansão da cidade pertencia integralmente ao poder público e este

\footnotetext{
${ }^{3}$ Durante a reunião que elegeu a região de Campinas para a implantação da nova capital, Dom Emanuel Gomes de Oliveira, arcebispo de Goiás, sugeriu que a sub-comissão técnica montada pudesse contar com o parecer de algum técnico de grande projeção. A sugestão de Dom Emanuel foi acatada por Ludovico e este contratou Armando de Godoy que, para isso, veio à Campinas acompanhado dos engenheiros Benedito Neto de Velasco e Américo de Carvalho Ramos. Godoy homologou a decisão da comissão sem restrições. O engenheiro apresentou um extenso relatório sobre a mudança da capital. Iniciou o relatório afirmando que as conclusões apontadas foram resultados das visitas à cidade de Campinas, bem como a leitura do documento final da comissão técnica da escolha do lugar para a implantação da futura capital. Godoy, antes de abordar propriamente a região de Campinas, fez várias intervenções no relatório descrevendo as razões para o atraso do Estado de Goiás. Entre elas, o engenheiro ressalta a falta de uma "cidade moderna".
} 
resistia em ampliar os limites da cidade, conforme recomendara Corrêa Lima, antes que a cidade projetada houvesse sido plenamente implantada.

Era bastante intrincada a relação entre o governo estadual e a empresa responsável pela construção da cidade. Por um lado, o governo não parecia disposto a abrir mão do controle do parcelamento urbano; por outro lado, os irmãos Coimbra Bueno, responsáveis por todas as obras do governo, tinham total liberdade no que tangia a contratação e disposição dos funcionários responsáveis pelo erguimento dos edifícios $^{4}$. Isso Ihes conferia uma força considerável em todas as negociações com o poder público na defesa de seus interesses tanto como construtores quando na condição de especuladores donos de grande parcela de terras nos arredores da cidade. O arquiteto acabou se mostrando o elo mais fraco dessa relação tensa e vários estudiosos creditam a essa relação, entre o técnico e os construtores, a verdadeira causa do rompimento e da revisão de alguns princípios urbanísticos nos primeiros anos de Goiânia.

Mesmo depois que Attilio Corrêa Lima já havia se desligado da construção de Goiânia continuou a ter problemas com os Coimbra Bueno até a década de 1940. Já em 1943, o arquiteto foi obrigado a defender sua posição como autor do projeto original da de Goiânia através de um processo contra a empresa de engenharia dos Coimbra Bueno se utilizando para tanto de documentos assinados pelo Instituto dos Arquitetos do Brasil, pelo governador Pedro Ludovico Teixeira.

Efetivamente, em 1937, o engenheiro Jerônimo Coimbra Bueno no papel de responsável pela Superintendência- Geral das Obras da Nova Capital elabora um relatório sistematizando os principais elementos do Plano de Goiânia. Manso13 afirma que neste documento a principal preocupação era quanto à definição das plantas da cidade e daí se pode inferir que a partir do lapso de tempo entre a contratação inicial de Corrêa Lima, seu período de trabalho na elaboração de suas ideias para o traçado da cidade, os projetos de alguns dos principais prédios a serem construídos nos primeiros anos e a preocupação com a definição do traçado urbanístico da cidade pelo engenheiro as plantas foram alteradas nesse meio tempo. As linhas do plano foram definidas com vários estudos pormenorizados, como zoneamento, detalhes de quadras, loteamentos, vias de circulação, tráfego, avenida de contorno, vias de acessos externo e melhoramento e ampliação da rede rodoviária do estado, bem como a definição de planos econômico-sociais da região. Ainda segundo Manso, as

\footnotetext{
${ }^{4} \mathrm{O}$ próprio Armando de Godoy, a certa altura, como funcionário da prefeitura, sofreu diferentes pressões dos Coimbra Bueno.
} 
propostas contidas nesse relatório foram feitas sob a orientação de Armando de Godoy e submetidas à apreciação do professor Anhaia de Melo.

Percebem-se as mudanças efetuadas no plano original de Corrêa Lima para a região comercial do setor central, por exemplo, no sentido, segundo os irmãos construtores, de favorecer o livre estabelecimento da oferta e da procura já que o plano original previa uma área considerada muito extensa. Godoy sustentava que uma área comercial demasiadamente grande prejudicaria a cidade devido a um número enorme de pequenos comércios que seriam necessários para ocupar toda a área e estas acabariam por ter um movimento de vendas deficiente incapaz de imprimir desenvolvimento à cidade.

As modificações introduzidas por Godoy ao plano original de Corrêa Lima contemplaram algumas questões referentes ao próprio núcleo da concepção do arquiteto, ou seja, a praça central da cidade, ponto focal da perspectiva imaginada por Lima. Embora Godoy não altere a perspectiva projetada por Corrêa Lima nem a relação hierárquica do conjunto da praça com o restante da cidade, Godoy altera a configuração interna da praça ao eliminar os anéis viários que, segundo Attilio, protegeriam os edifícios dbalbúrdia da vida cotidiana deslocando o trânsito para fora. Godoy de certa maneira coloca a praça perto da cidade trazendo a vida citadina e por consequência o trânsito para dentro dela.

Mas sem sombra de dúvidas a grande modificação no plano original se deu com a modificação do Setor Sul, previsto para moradias unifamiliares de alto nível. A discordância se dá no âmbito de discussão sobre as cidades-jardins. As posições do arquiteto Corrêa Lima, conforme se pode depreender da figura 3, e do engenheiro Godoy, conforme a figura 4, os colocam em pontos diametralmente opostos. Godoy retomou sua ideia da cidade jardim para Goiânia - ela havia sido proposta ainda em 1933 - desenhando um bairro inspirado na cidade de Redburn, a primeira a adotar a solução do cul de sac. 
Figura 3 - Plano original do núcleo inicial da cidade de Goiânia proposto por Attilio Corrêa Lima.

Fonte: Manso, 2001:221

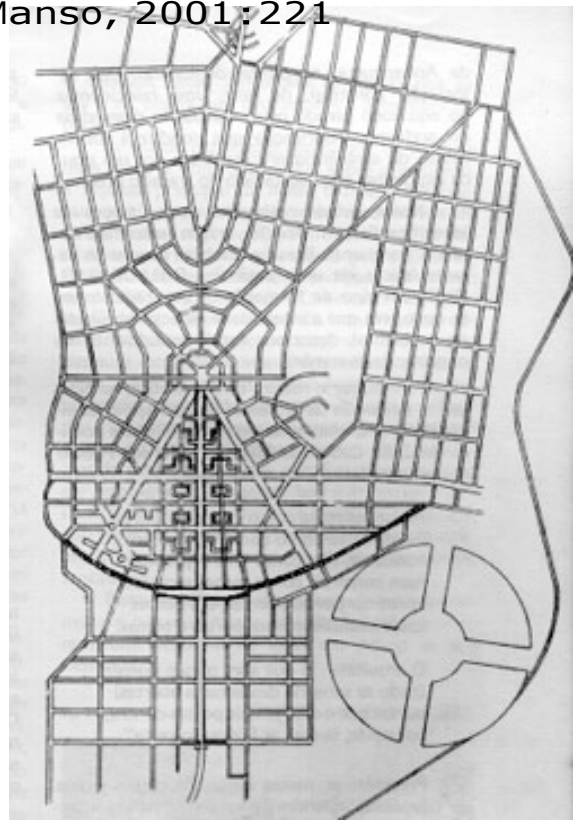

Figura 4 - Plano definitivo do núcleo inicial de Goiânia proposto por Armando de Godoy.

Fonte: MANSO,2001:222:

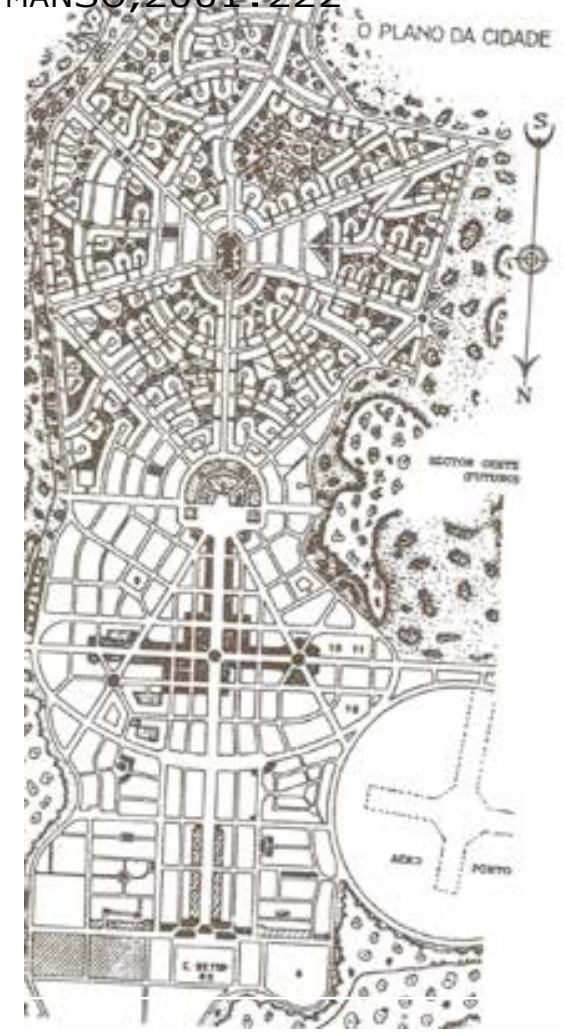

Godoy previu no novo plano para o Setor Sul uma separação profunda entre o tráfego e as áreas destinadas à moradia, sendo esse particular que possibilita a distinção entre o acesso de serviço e o acesso social, Corrêa Lima conheceu as cidades-jardins através da cidade dormitório de Paris de Sallier, nos arredores de Paris, criada para solucionar o déficit de moradias depois da Primeira Guerra. Essa concepção foi bastante criticada à época. Assim, é possível compreender a resistência de Corrêa Lima na adoção da solução das cidades-jardins para Goiânia, conforme proposto por Godoy ainda em 1933, uma vez que o arquiteto não acreditava no êxito do modelo considerando a estrutura e as dificuldades sócio-econômicas do centrooeste brasileiro. Godoy insistiu na adoção da cidade- jardim apostando na distinção entre a cidade antiga e a cidade moderna, em sua ação civilizadora e econômica. 
Godoy falava de urbanização com forma dinâmica, apontando para a necessidade de estabelecer um maior contato entre os citadinos e a natureza.

Outra questão de fundo dentro do embate teórico nos primeiros anos de Goiânia se deu também por meio dos referenciais teóricos de Godoy. Trata-se da opção do engenheiro pela solução das cidades satélites para controlar a expansão da nova cidade. No relatório de 1937 e que se transformou no plano diretor da cidade aprovado em 1938, já consta uma cidade satélite, Campinas. Godoy sugeriu o rígido controle no parcelamento da cidade para que quando esta tivesse atingido a total ocupação de seu loteamento outro pudesse ser criado em terreno comprado pelo próprio estado, observando a manutenção de um cinturão verde ao redor do plano original.

Os construtores Coimbra Bueno adotaram, ao menos no discurso, a ideia defendida por Godoy da expansão de Goiânia através das cidades satélites, uma vez que ao que tudo indica nem mesmo os irmãos Coimbra Bueno demonstraram real confiança na exequibilidade das cidades satélites. Documentos demonstram que, em um mesmo relatório, Jerônimo Coimbra Bueno avaliava o intento de Godoy de forma contraditória. Primeiramente, o construtor diz: "o doutor Armando de Godoy sugeriu que o núcleo de Goiânia tivesse uma população limitada pelo próprio plano de urbanização" (ALVARES, 1942: 36). Em outro momento, no mesmo relatório, pode-se ler:

Aqui para Goiânia, não podemos garantir que o plano seja executado como quer o doutor Armando de Godoy, isto é, que a cidade não passe dos contornos para os quais foi projetada - é muito possível que a evolução de nossa sociedade venha a determinar orientação diferente, determinando a extensão da cidade para fora do perímetro atualmente projetado. Por isso, é necessário prever uma legislação que faculte esta evolução. Isto dificilmente será conseguido se o Estado vender, em vez de arrendar, faixas de terras, em torno da cidade (ALVARES, 1942: 36).

A manifestação de Godoy sobre as cidades-jardin vai de encontro com o entusiasmo que as mesmas causam na época e nos anos 1930 tais experiências ainda contavam com poucos anos das suas primeiras implantações mundo afora. Godoy propõe uma solução que é, naquele momento, praticada em vários países e se encontra na vanguarda da arquitetura moderna.

Aqui cabe, no entanto, uma especulação se a solução proposta por Corrêa Lima - distanciada das cidades-jardins - mas igualmente pertencente ao repertório moderno no que diz respeito ao que existia além dos limites de Goiânia fosse a mais 
sensata naquele momento levando-se em conta as dificuldades inerentes a uma empresa desta em pleno sertão brasileiro. Como já dito anteriormente, podemos detectar uma incipiente tentativa de pensar Goiânia como ponto focal da região que a cerca quando os planos originais conectam a capital a Campinas articulando a região através de uma importante avenida pensada para absorver o comércio mais dinâmico ou o trânsito mais pesado, transformando um antigo caminho usual da região em uma das principais avenidas do arranjo urbano proposto pelo arquiteto.

Resta apenas a especulação já que com a aprovação do Plano Diretor de Goiânia em 1938, os próprios irmãos Coimbra Bueno subvertem todos os cuidados que Corrêa Lima e Godoy imaginaram com a expansão da nova cidade e aprovaram aproveitando-se de suas relações especiais com o governo do Estado - juntamente com o próprio plano diretor o parcelamento do Setor Coimbra nos arredores de Campinas e transformaram-se, assim, nos primeiros especuladores criando as condições para que as condições estabelecidas no plano soçobrassem.

\section{Referências}

ALVARES, Geraldo Teixeira. A Luta na Epopéia de Goiânia: Uma Obra da Engenharia Nacional. Rio de Janeiro: Oficina Gráfica do Jornal do Brasil, 1942.

CORRÊA LIMA, Attilio. Goiânia. Arquitetura e Urbanismo, ano 2. Rio de Janeiro, 1937.

.... E assim nasceu uma linda cidade no sertão. Correio da Noite, 4.7.1942, Rio de Janeiro.

GRAEFF, Edgard. Goiânia: 50 anos. Série: Oito vertentes e dois momentos de síntese da arquitetura brasileira. Brasília: MEC-SESU, 1985.

MAIA, Francisco Prestes. O plano regional de Santos. São Paulo: Prefeitura Municipal, 1950.

MANSO, Celina Fernandes Almeida. Goiânia; Uma Concepção Urbana e Moderna Um Certo Olhar. Goiânia: Edição do autor, 2001.

SEGAWA, Hugo. Arquiteturas no Brasil. São Paulo: Edusp, 1999. 